\title{
Do histopathologic findings improve by increasing the sample size in cholecystectomies?
}

\author{
Tumay Ozgur ${ }^{1 *}$, Serhat Toprak', Ali Koyuncuer², Muhammed Guldur², Gurman Bayraktar ${ }^{2}$ and Mehmet Yaldiz ${ }^{1}$
}

\begin{abstract}
Background: Gallbladder diseases present with cholelithiasis in a wide spectrum of adenomas and cancers. Two or three specimens are sampled in cholecystectomies in routine pathology practice. The aim of this study was to investigate the increase in frequency of histologic alterations in cholecystectomies, particularly precancerous lesions, by increasing the sample size to understand the carcinoma pathway.

Methods: Cholecystectomies of 432 patients with pathology records and materials from two medical centers were collected, and two groups were created. Initial data with two or three samples were allocated to Group 1 and the new six samples with the initial ones were allocated to Group 2. Hematoxylin and eosin (H\&E) sections were examined for histopathologic alterations, and periodic acid-Schiff (PAS) Alcian blue (pH 2.5) and high iron diamine ( $\mathrm{pH}$ 2.5) stains were used to signify the mucin profile in case of metaplasias. For the comparison of findings, non-parametric tests, McNemar's tests, chi-squared tests and Fisher's exact test were performed.

Results: Of the 432 patients, 308 (71.3\%) patients were female and 124 (28.7\%) patients were male. The mean age of patients was $47.9 \pm 14.6$ years. Cholesterolosis was observed in 95 (22\%) patients in Group 1 and 108 (25\%) patients in Group 2. Gallstones were detected in 255 (59\%) of the cholecystectomies. There was a significant difference between Group 1 and Group 2 by increasing the sample size when we compared cholesterolosis, metaplasia and polyps $(P<0.05)$. Cholecystitis and dysplasia rates were the same in both of the groups. There was no cancer determined.
\end{abstract}

Conclusion: Increasing the sample size in cholecystectomies increased the diagnosis of some histologic alterations, but further studies with a larger number of samples over a longer period time might increase the ability to determine precancerous lesions and concomitants.

Keywords: Cholecystectomy, Sample size, Precancerous lesion

\section{Background}

There are various lesions of the gallbladder that require surgical intervention. Gallstones and chronic cholecystitis are the most common pathologies, accompanied by cholesterolosis, adenomatous proliferation of mucous glands, metaplasia, dysplasia and hyperplasia [1]. Gallbladder cancer is the fifth most common malignant neoplasm of the gastrointestinal tract $[2,3]$.

Metaplasia, dysplasia and hyperplasia are accepted as precursor lesions of the gallbladder; however, there is insufficient literature about the relationship of these lesions and gallbladder cancer. Detecting these lesions

\footnotetext{
* Correspondence: ozgurtumay@yahoo.com

'School of Medicine, Pathology Department, Mustafa Kemal University, 31100 Serinyol-Hatay, Turkey

Full list of author information is available at the end of the article
}

could provide a better understanding of carcinogenesis, risk factors and selecting prophylactic cholecystectomy patients. In this study, we investigated the possibility of determining increased rates of lesions, particularly precancerous lesions in gallbladders, which are the most common surgical material of daily pathology practice, with increased sample size.

\section{Methods}

A prospective analysis was conducted at the Pathology Laboratory, Hatay Antakya State Hospital, and the Pathology Department, Mustafa Kemal University, Turkey, between October 2011 and May 2012, using the records and materials of laparoscopic cholecystectomies. The

\section{Biomed Central}


ethical committee on human research at Mustafa Kemal University approved the protocol for all human research.

The histopathologic examination consisted of an initial macroscopic examination of the specimen and suspicious areas with two or three samples. These specimens were allocated to Group 1.

The residual specimens were then collected in Mustafa Kemal University Pathology Department, and the fundus, body and neck of the gallbladders were sampled randomly. These new six samples with initial ones were allocated to Group 2.

These samples were then embedded in paraffin, sectioned, stained with hematoxylin and eosin (H\&E), and examined under an Olympus BX53 (Olympus, Tokyo, Japan) light microscope. In case of existing metaplasia, the mucin profile was signified histochemically by neutral mucin, periodic acid-Schiff (PAS) Alcian blue $(\mathrm{pH} 2.5)$ and high iron diamine ( $\mathrm{pH} 2.5)$. All histologic alterations described on the pathologists' reports were included in the study. The presence of acute or chronic cholecystitis, gallstones, cholesterolosis, pyloric intestinal metaplasia, dysplasia, carcinoma, or polyps was analyzed as pathological data.

\section{Statistical analysis}

Statistical evaluations were performed using SPSS 13.0 (IBM, Armonk, NY, USA) for Windows, and $P<0.05$ was considered statistically significant. For the comparison of findings, non-parametric tests, McNemar's tests, chi-squared tests and Fisher's exact test were performed.

\section{Results}

Of the 432 cases, $308(71.3 \%)$ patients were female and 124 (28.7\%) patients were male. Patients' ages varied from 18 to 84 years. The mean age of patients was $47.9 \pm 14.6$ years. Gallstones were obtained in 255 (59\%) cholecystectomies. There were no stones in 177 (41\%) gallbladders. The distributions of histologic alterations are shown in Table 1. Acute cholecystitis was observed in 31 (7.2\%) patients, while chronic cholecystitis was observed in 401 (92.8\%) patients in Group 1 and Group 2. There was no significant difference between them $(P>0.05$, kappa $=0.965$ ).

Cholesterolosis was observed in $95(22 \%)$ patients in Group 1 and 108 (25\%) patients in Group 2. There was a statistically significant difference between both of the groups $(P=0.001$, kappa $=0.904)$. There were ten polyps $(2.3 \%)$ in Group 1: seven (1.6\%) were cholesterol polyps (Figure 1), one $(0.2 \%)$ was a fibroepithelial polyp (Figure 2 ), one $(0.2 \%)$ was a papillary adenoma, one $(0.2 \%)$ was a tubular adenoma (Figure 3$)$, and one $(0.2 \%)$ case had both cholesterol and fibroepithelial polyps.
Table 1 The distribution of histologic alterations within the groups

\begin{tabular}{lllll}
\hline & Group 1 (n/\%) & Group 2 (n/\%) & $\boldsymbol{P}$ & Kappa \\
\hline Acute cholecystitis & $31(7.2 \%)$ & $31(7.2 \%)$ & $>0.05$ & 0.965 \\
Chronic cholecystitis & $401(92.8 \%)$ & $401(92.8 \%)$ & & \\
Non-cholesterolosis & $337(78 \%)$ & $324(75 \%)$ & 0.001 & 0.904 \\
Cholesterolosis & $95(22 \%)$ & $108(25 \%)$ & & \\
Non-metaplasia & $407(94.2 \%)$ & $391(91.2 \%)$ & 0.0001 & 0.739 \\
Pyloric metaplasia & $23(5.3 \%)$ & $38(8.8 \%)$ & & \\
Intestinal metaplasia & $2(0.5 \%)$ & $3(0.7 \%)$ & & \\
Non-polyp & $422(97.8 \%)$ & $416(96.6 \%)$ & 0.031 & 0.76 \\
Cholesterol polyp & $7(1.6 \%)$ & $11(2.5 \%)$ & & \\
Fibroepithelial polyp & $1(0.2 \%)$ & $2(0.5 \%)$ & & \\
Tubular adenoma & $1(0.2 \%)$ & $1(0.2 \%)$ & & \\
Papillary adenoma & $1(0.2 \%)$ & $1(0.2 \%)$ & & \\
Non-dysplasia & $430(99.5 \%)$ & $430(99.5 \%)$ & $>0.05$ & 1.0 \\
Low grade dysplasia & $2(0.5 \%)$ & $2(0.5 \%)$ & & \\
High grade dysplasia & $0(0 \%)$ & $0(0 \%)$ & & \\
Carcinoma & $0(0 \%)$ & $0(0 \%)$ & $>0.05$ & 1.0 \\
\hline
\end{tabular}

There were $16(3.2 \%)$ polyps in Group 2: $11(2.5 \%)$ were cholesterol polyps, two $(0.5 \%)$ were fibroepithelial polyps, one $(0.2 \%)$ was a papillary adenoma, one $(0.2 \%)$ was a tubular adenoma, and one $(0.2 \%)$ case had both cholesterol and fibroepithelial polyps. There was a statistically significant difference between the two groups $(P=0.031$, kappa $=0.762)$.

Metaplasia was observed in $25(5.8 \%)$ of the cases in Group 1: $23(5.3 \%)$ of them were pyloric metaplasia (Figure 4$)$, while two $(0.5 \%)$ were intestinal. Forty-one (9.5\%) cases in Group 2 had metaplasia: 38 (8.8\%) were pyloric and three $(0.7 \%)$ were intestinal. There was a significant difference between the two groups when comparing metaplasia $(P=0.0001$, kappa $=0.739)$.

We did not diagnose any carcinoma in this study period. However, there was mild dysplasia in two (0.5\%) of the cases in both of the groups, and there was no significant difference between them $(P>0.05$, kappa $=1.0)$.

\section{Discussion}

Gallbladder carcinoma is rarely diagnosed in precancerous stages due to its occult evolution and non-specific symptoms. There is little knowledge about its etiology or pathogenesis, and determining precursor lesions is difficult. Environmental and genetic risk factors are important in carcinoma development. There are two genetic alterations: adenoma-carcinoma sequence and the metaplasia-dysplasia-carcinoma sequence [4-6]. Gallbladder carcinoma is incidentally discovered during cholecystectomies performed for cholelithiasis or cholecystitis. Diagnosis and sampling of small-sized and flat epithelial 


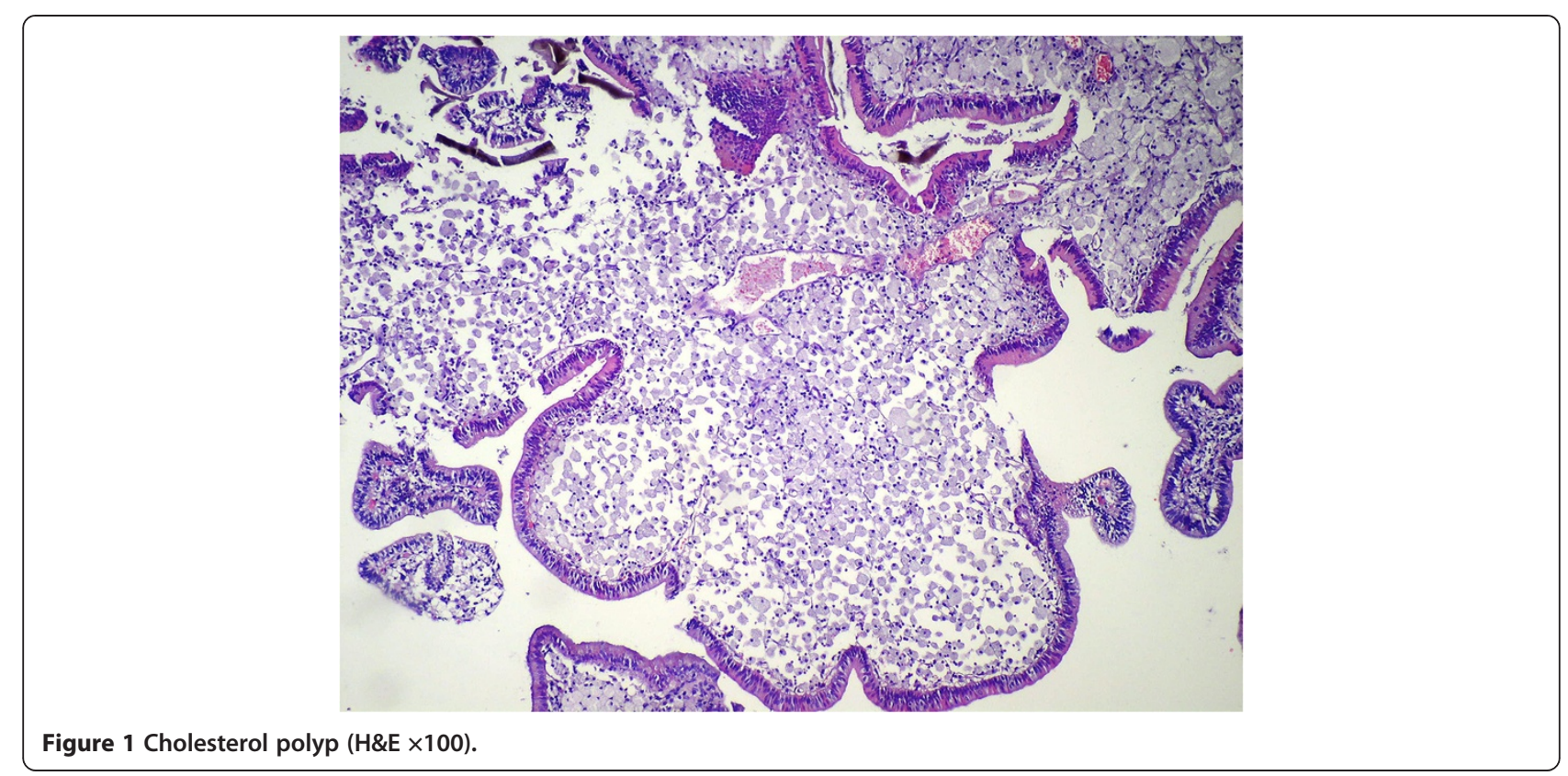

lesions in early stages is difficult; therefore, histopathologic evaluation of cholecystectomy specimens is important [7]. Pyloric metaplasia is more frequent than intestinal metaplasia in cholecystectomies $[4,5,8]$. We observed pyloric metaplasia predominance in both of our study groups with 23 (5.3\%) cases in Group 1 and 38 (8.8\%) cases in Group 2, similar to the literature. Metaplastic epithelium is more susceptible to malignant transformation than the normal epithelium [9]. We determined low grade dysplasia in two $(0.5 \%)$ cases, and there was no increase in the prevalence of this lesion with the increased sample size. Besides this observation, there was no significant relationship between metaplasia and dysplasia. In contrast to this study, Mazlum et al. observed metaplasia in 18 out of 24 dysplastic gallbladders either adjacent to or within the dysplastic epithelium [10]. MeirellesCosta $e t$ al. also found an association between pyloric metaplasia and dysplasia, supporting the metaplasiadysplasia-carcinoma sequence [11].

The discrepancies of our results might be related to the smaller population of our study group and the short interval of the study. On the other hand, this disease

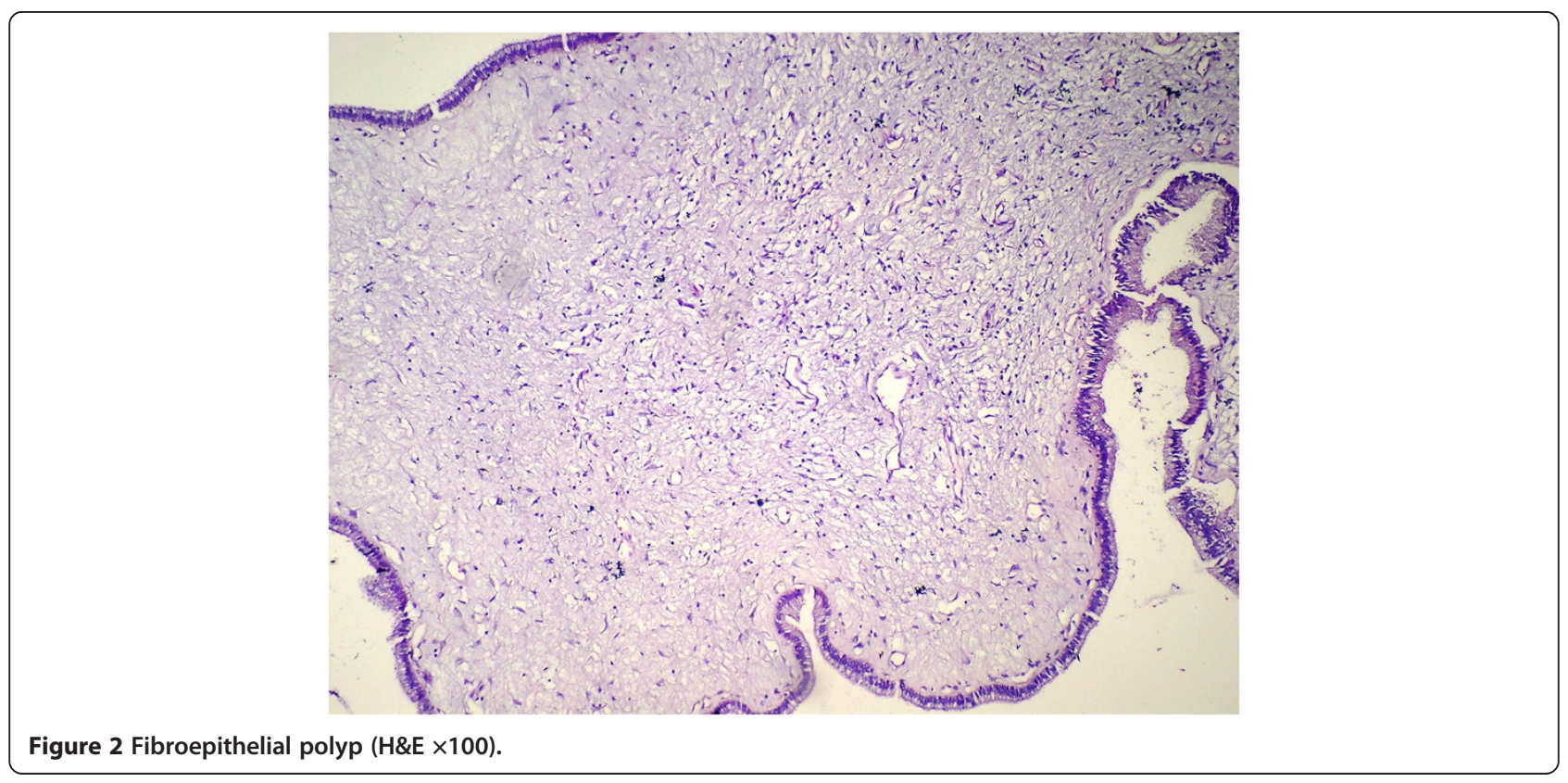




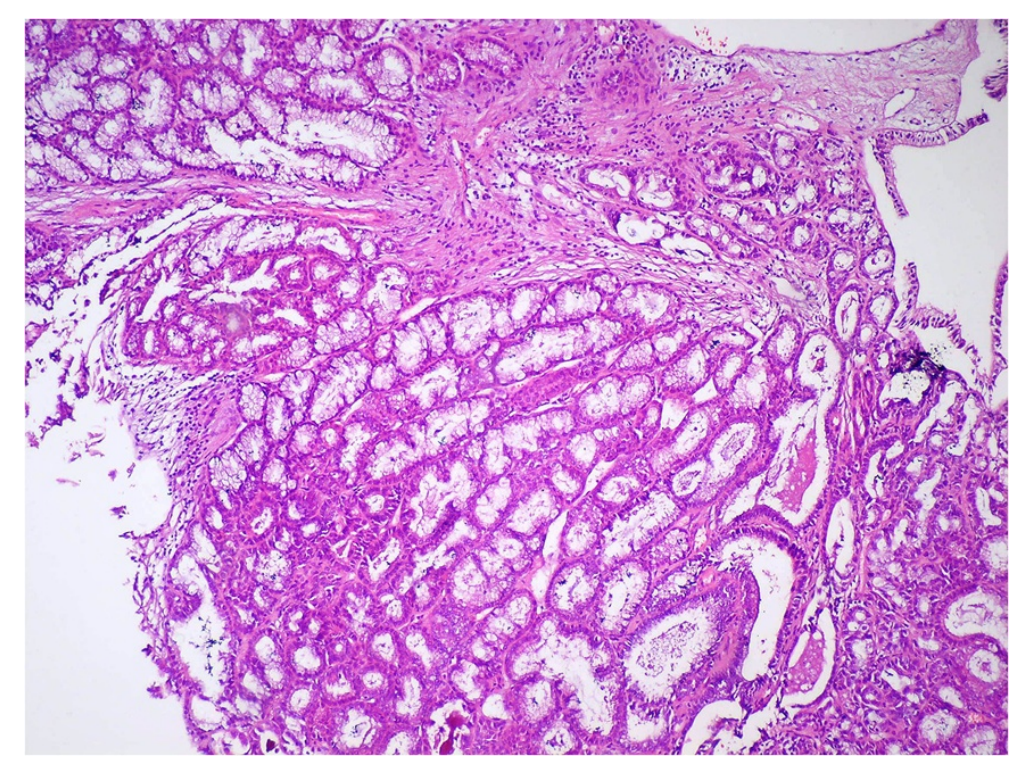

Figure 3 Tubular adenoma with low grade dysplasia (H\&E $\times 100)$.

progresses slowly and a longer follow-up period should be planned to obtain results that are similar to the current literature.

Gallbladder polyps present with conditions differing from cholesterol polyps to adenomas. Cholesterol polyps are one of the most frequent types stated in various studies $[10,12,13]$. Similar to the literature, we detected $16(3.2 \%)$ polyps in Group 2 with the increased sample size, and $11(2.5 \%)$ of those were cholesterol polyps. This variant of polyps is defined as the polypoid form of cholesterolosis [14]. Cholesterolosis is characterized by the accumulation of cholesterol esters in epithelioid histiocytes in the hyperplastic mucosa of the gallbladder [15]. We found cholesterolosis in 95 (22\%) patients in Group 1 and 108 (25\%) patients in Group 2, with a significant difference between them. These ratios were higher when compared to the Mazlum et al. study, which reported $13.3 \%$ of cholesterolosis cases from the Western part of Turkey [10]. Parallel to our study, Bolat et al. detected cholesterolosis in 14 (18.7\%) patients in their study [16]. In our geographical area, the population has a traditional Eastern Mediterranean diet, which is

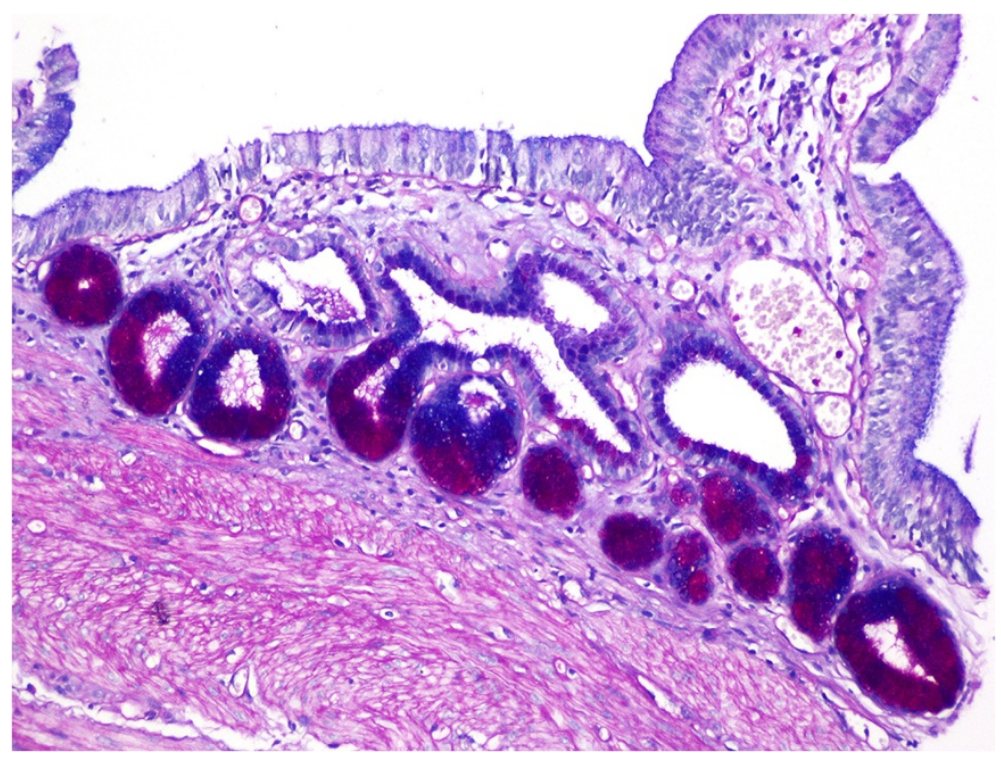

Figure 4 Pyloric metaplasia in mucosa (PAS Alcian blue $\times 100$ ). 
high in carbohydrates and fat, and could result in metabolic syndrome, particularly in women with a higher body mass index (BMI). We also found more cholesterol polyps and cholecystitis in females compared to males.

Adenomas are rare lesions of the gallbladder, and can be identified as tubular, papillary and tubulopapillary [17]. We observed two (0.4\%) adenomas in our study: one $(0.2 \%)$ case was tubular and the other $(0.2 \%)$ papillary. There was low grade dysplasia within the tubular adenoma, which is described frequently in other studies $[9,17]$. However, we did not detect any carcinoma focus in our cases. This could be related to the rare malignant transformation and size of the adenoma in gallbladders when compared to other gastrointestinal organs [18]. On the other hand, we should keep in mind that the development of laparoscopic surgical techniques and the recommendation of cholecystectomy for cholelithiasis and cholecystitis with long evolution have reduced the cancer cases [19].

We determined higher ratios of polyp, cholesterolosis and metaplasia when the sample size was increased in Group 2. The difference of the results of the two groups in non-neoplastic lesions might be due to the neglect of the sampling and evaluation of the lesions. However, preneoplastic lesions, such as metaplasia and dysplasia, cannot be determined with macroscopic examination, and at this point increasing the number of specimens becomes essential. Parallel to this study, the importance and value of macroscopic sampling has been highlighted in other studies $[4,5]$. Mukhopadhyay et al. also determined that in most cases of dysplasia with a coexistent metaplastic lesion, dysplasia arises from precursor lesions, not directly from an inflammatory background [4]. Therefore, sampling of the epithelium, unrelated with injured and inflamed zones in gallbladders, and with no mucosal irregularity or thickness for noticing dysplasia, comes into question. On the other hand, the detection of focal epithelial changes is a result of the number of sections examined. Duarte et al. included fewer patients but used far more extensive sampling. They found that a single random histologic section detected less than one third of metaplasias and dysplasias in the gallbladder, and used whole mapping of the gallbladders in their study [5].

\section{Conclusions}

All histologic findings, with the exception of cholelithiasis and cholecystitis, had low incidence upon examination of the cases. However, there was a significant difference among metaplasia, polyp and cholesterolosis evaluation between the two groups, suggesting that the increased sample size would raise the possibility of determining more histologic lesions. Further studies with a greater number of samples and a longer follow-up period might increase the detection of precancerous lesions and concomitants.

\section{Abbreviations}

BMI: Body mass index; H\&E: Hematoxylin and eosin; PAS: Periodic acid-Schiff.

\section{Competing interests}

The authors declare that they have no competing interests.

\section{Authors' contributions}

TO designed the study, searched the literature and drafted the manuscript. ST sampled the materials and prepared the sections. AK searched the literature, examined the materials and prepared the figures. MG and GB examined the materials. MY participated in study design and coordination. All authors read and approved the final manuscript.

\section{Acknowledgements}

The authors would like to thank to Cahit Ozer MD, Associate Professor of Family Medicine, for help with the statistical analyses of the study.

\section{Author details}

${ }^{1}$ School of Medicine, Pathology Department, Mustafa Kemal University, 31100 Serinyol-Hatay, Turkey. ${ }^{2}$ Pathology Laboratory, Hatay Antakya State Hospital, Antakya-Hatay, Turkey.

Received: 12 June 2013 Accepted: 19 September 2013 Published: 1 October 2013

\section{References}

1. Rosai J: From Gall bladder and extrahepatic bile ducts. In Rosai and Ackerman's Surgical Pathology, Volume 1. 9th edition. Edited by Rosai J. New York, NY: Mosby; 2000:1035-1060.

2. Bartlett DL: Gall bladder cancer. Semin Surg Oncol 2000, 19:145-155.

3. Lowenfels $A B$, Maisonneuve P, Boyle P, Zatonski WA: Epidemiology of the gall bladder cancer. Hepatogastroenterology 1999, 46(Suppl 27):1529-1532.

4. Mukhopadhyay S, Landas SK: Putative precursors of gall bladder dysplasia: a review of 400 routinely resected specimens. Arch Pathol Lab Med 2005, 129:386-390.

5. Duarte I, Llanos O, Domke H, Harz C, Valdivieso V: Metaplasia and precursor lesions of gall bladder carcinoma. Frequency, distribution and probability of detection in routine histologic samples. Cancer 1993, 72:1878-1884

6. Albores-Saavedra J, Alcantra-Vazquez A, Cruz-Ortiz H, Herrera-Goepfert R: The precursor lesions of invasive gall bladder carcinoma. Hyperplasia, atypical hyperplasia and carcinoma in situ. Cancer 1980, 45:919-927.

7. Sasatomi E, Tokunaga O, Miyazaki K: Precancerous conditions of gall bladder carcinoma: overview of histopathologic characteristics and molecular genetic findings. J Hepatobiliary Pancreat Surg 2000, 7:556-567.

8. Stancu M, Caruntu ID, Gıuşca S, Dobrescu G: Hyperplasia, metaplasia, dysplasia and neoplasia lesions in chronic cholecytitis- a morphologic study. Rom J Morph Embryol 2007, 48(Suppl 4):335-342.

9. Mukada T, Andoh N, Matsushiro T: Precancerous lesions of the gallbladder mucosa. Tohoku J Exp Med 1985, 145:387-394.

10. Mazlum M, Dilek FH, Yener AN, Tokyol C, Aktepe F, Dilek ON: Profile of gallbladder diseases diagnosed at Afyon Kocatepe University: a retrospective study. Turk Patoloji Derg 2011, 27(Suppl 1):23-30.

11. Meirelles-Costa AL, Bresciani CJC, Perez RO, Bresciani BH, Siqueira SA Cecconello I: Are histologic alterations observed in the gall bladder precancerous lesions? Clinics 2010, 65(Suppl 2):43-50.

12. Terzi C, Sökmen S, Seçkin S, Albayrak L, Uğurlu M: Polypoid lesions of the gall bladder: report of 100 cases with special reference to operative indications. Surgery 2000, 127:622-627.

13. Escalona A, León F, Bellolio F, Pimentel F, Guajardo M, Gennero R, Cruz JP, Viviani $P$, Ibáñez L: Gallbladder polyps: correlation between ultrasonographic and histopathologic findings. Rev Med Chil 2006, 134:1237-1242.

14. Jørgensen $\mathrm{T}$, Jensen $\mathrm{KH}$ : Polyps in the gallbladder. A prevalence study. Scand J Gastroenterol 1990, 25:281-286.

15. Owen CC, Bilhartz LE: Gallbladder poyps, cholesterolosis, adenomyomatosis and acute acalculouscholcytitis. Semin Gastrointest Dis 2003, 14:178-188. 
16. Bolat F, Kayaselcuk F, Nursal TZ, Bal N, Tuncer I: The correlation of the histopathologic findings by increasing the sample size in cholecystectomies. Turk J Pathol 2007, 23(Suppl 3):137-142.

17. Hansel DE, Maitra A, Argani P: Pathology of the gall bladder: a review. Cur Diagn Pathol 2004, 10:304-317.

18. Roa I, de Aretxabala X, Araya JC, Roa J: Preneoplastic lesions in gallbladder cancer. J Surg Oncol 2006, 93:615-623.

19. Orth K, Beger HG: Gall bladder carcinoma and surgical treatment. Langenbecks Arch Surg 2000, 385(8):501-508.

doi:10.1186/1477-7819-11-245

Cite this article as: Ozgur et al:: Do histopathologic findings improve by increasing the sample size in cholecystectomies? World Journal of Surgical Oncology 2013 11:245.

\section{Submit your next manuscript to BioMed Central and take full advantage of:}

- Convenient online submission

- Thorough peer review

- No space constraints or color figure charges

- Immediate publication on acceptance

- Inclusion in PubMed, CAS, Scopus and Google Scholar

- Research which is freely available for redistribution 